\title{
OS PARADIGMAS CULTURAIS E SEUS IMPACTOS NA SAÚDE DO HOMEM
}

\author{
Bruna Tayná Ortiz Moreira \\ Luiza Venturini Helaehil \\ Clarice Santana Milagres \\ 1,2Discentes do Curso de Enfermagem, Centro Universitário \\ Fundação Hermínio Ometto - FHO Uniararas \\ ${ }^{3}$ Doutora em Odontologia/Saúde Coletiva na Universidade Estadual de Campina
}

INTRODUÇÃO: A Política Nacional de Atenção Integral a Saúde do homem (PNAISH) foi lançada em 2009, com a finalidade de promover melhoria das condições de saúde da população masculina, e a redução da morbimortalidade deste grupo populacional. O comprometimento com a saúde do homem que vem da baixa adesão aos serviços de saúde pública tem influencias de determinantes socioculturais e barreiras institucionais. Eles são vistos como invulneráveis, levando ao cuidado reduzido e exposição a situações de riscos. Seu atendimento na atenção primária não costuma suprir suas necessidades e demandas de saúde, que na maioria das vezes não são reconhecidas, além de possuírem relacionamentos sempre comprometidos devido uma socialização segmentada por gênero, onde mesmo eles identificando o serviço de saúde como positivo e benéfico para o seu bem-estar, acaba surgindo impactos e lacunas no seu atendimento. O homem acaba se encontrando em situações de saúde desfavorável, devido seus comportamentos e modo de viver. Possuem certa limitação em construir sua identidade, não são envolvidos na questão saúde e doença e se veem como responsáveis pela prevenção e cuidado da sua própria saúde, o que reforça a associação de masculinidade e independência, além de possuírem necessidade em ser vistos com singularidades nas relações de gêneros, sendo eles estimulados a manifestar sua virilidade, rejeitando comportamentos tidos como femininos, o que leva ao padrão de masculinidade que é idealizado pelo modo de serem vistos poucos viris ou afeminados. OBJETIVOS: discutir a articulação entre os aspectos culturais e os fatores de risco relacionados à maior morbimortalidade e ações voltadas para a assistência da saúde do homem. MÉTODOS: trata-se de uma revisão de literatura que utilizou publicações inseridas nas bases de dados eletrônicos científicos Pubmed Medline, Scielo, Biblioteca Virtual da Saúde (Bireme/LILACS) e Science Direct; realizando buscas pelas últimas pesquisas entre os anos de 2007 e 2017. 
RESULTADOS: Identificou-se onze artigos, sendo oito os artigos que compuseram a amostra desse projeto. Dentre os artigos selecionados, constatou-se que há maior prevalência de fatores como feminização da saúde masculinidade/fatores culturais e temor relacionado ao trabalho/incompatibilidade de horários que interferem diretamente no processo saúde-doença do homem. CONCLUSÃO: A relação entre os aspectos culturais e os fatores de risco relacionados à maior morbimortalidade é diversificada e pouco se faz em relação às ações voltadas para a assistência da saúde do homem. Entretanto, observa-se que atualmente há um processo de mudança cultural relacionado ao próprio homem e sua preocupação com a saúde, mesmo ainda existindo muitos paradigmas a serem quebrados. $O$ grande desafio dos profissionais é conseguir a atenção dos homens antes que estes já estejam doentes, através de ações preventivas e de promoção à saúde, sendo necessário também mudanças na cultura masculina, a fim de se compreender que tanto os homens quanto as mulheres, são igualmente vulneráveis e propensos a doenças quando não prevenidas.

Palavras-chave: Saúde do homem. Atenção à saúde. Gênero. 